\title{
METHYL JASMONATE AFFECTS POPULATION DENSITIES OF PHYTOPHAGOUS AND ENTOMOPHAGOUS INSECTS IN WHEAT
}

\author{
BAYRAM, A. - TONĞA, A. \\ Plant Protection Department, Agriculture Faculty, Dicle University \\ 21280 Diyarbakır, Turkey \\ (phone: +90-412-248-8509; fax: +90-412-248-8153) \\ *Corresponding author \\ e-mail:adton21@gmail.com \\ (Received 25 $5^{\text {th }}$ Aug 2017; accepted $4^{\text {th }}$ Dec 2017)
}

\begin{abstract}
Methyl jasmonate (MEJA), a well-known herbivore-induced plant volatile, promotes plant defences against various stress factors. The aim of this study was to investigate the effects of different doses of exogenously applied MEJA on the population densities of wheat insect pests and their natural enemies by employing three sampling methods (direct visual sampling, sweep net, sticky traps) in 2012 and 2013 under semi-arid conditions. MEJA treatments had repellent effects on aphids (Hemiptera: Aphididae), phytophagous thrips species (Thysanoptera: Phlaeothripidae and Thripidae) and hoverfly species (Diptera: Syrphidae), whereas it was attractive to wheat stem sawflies (Hymenoptera: Cephidae), lady beetle species (Coleoptera: Coccinellidae) and Collyria coxator (Hymenoptera: Ichneumonidae). MEJA treatments had no effect on aphid parasitoids abundances (Hymenoptera: Braconidae). The experimental outcomes varied, depending on plant phenology and sampling method. MEJA treatment also led to reductions in wheat yield and plant height. MEJA treatment could be beneficial as a natural pest control tool when certain species are targeted.
\end{abstract}

Keywords: semiochemical, predator, parasitoid, wheat insect pests, Triticum aestivum

\section{Introduction}

Wheat, Triticum aestivum L., one of the most important food crops, confronts many stress factors, including insect pests and microbial diseases. Insect pests such as aphids (Hemiptera: Aphididae) and thrips species (Thysanoptera: Phlaeothripidae) reduce grain yield by piercing and sucking the contents of stems, leaves and spikes, while the larvae of wheat stem sawfly species cause decreased yield and grain number by disrupting sap flow as they tunnel into host stems. Therefore, these pests may cause substantial yield losses (Seddigh and Bandani, 2012; Larsson, 2005; Özberk et al., 2005). Extensive use of insecticides is the mainstay method to minimize yield losses, but these treatments are unsustainable and environmentally damaging. Moreover, insecticides are only partially effective against some of the pests e.g., wheat stem sawflies owing to their cryptic egg laying and life cycle. In addition, the natural enemies of these pests can also be harmed by insecticides, which is counterproductive to controlling the pest populations. Therefore, management of insect pests requires better methods.

Plants under herbivore attack release volatile organic plant compounds (VOCs) to minimize damage by settled attackers or to prevent impending dangers (Kessler and Baldwin, 2001; Tan et al., 2012). These herbivore-induced plant volatiles (HIPVs) are not only repellent to insect herbivores, but they also encourage the foraging behavior of natural enemies of the pests (Boughton et al., 2006; Moraes et al., 2009; Mandour et al., 2013). Among a large variety of HIPVs, the jasmonates seem to be key components of 
plant defense systems (Lackman et al., 2011). Even though jasmonic acid (JA) is the most abundant volatile among the jasmonates, exogenous application of methyl jasmonate (MEJA) is generally more effective because of its greater volatility (Beltrano et al., 1998). Previous studies have demonstrated that MEJA induces plant defenses by increasing the activity of lipoxygenase and the production of C6-aldehydes, thus suppressing larval feeding by the hawkmoth Manduca sexta (Lepidoptera: Sphingidae) and the cabbage looper Trichoplusia ni (Lepidoptera: Noctuidae) (Avdiuskho et al., 1997). MEJA applications were also found to decrease the population growth of two phloem feeders, the green peach aphid Myzus persicae (Sulzer) (Hemiptera: Aphididae) on tomato plants (Lycopersicon esculentum) and the potato aphid Macrosiphum euphorbiae on potato plants (Solanum tuberosum) (Boughton et al., 2006; Brunissen et al., 2010). Population growth of the soybean aphid Aphis glycines Matsumura (Hemiptera: Aphididae) and the soybean thrips Neohydatothrips variabilis (Beach) (Thysanoptera: Thripidae) was reduced by MEJA application (Selig et al., 2016). In addition, MEJA treatment contributes to plant defenses by attracting natural enemies of pests. For example, MEJA-treated persimmon plants (Diospyros kaki) were found to be attractive to the lady beetle Chilocorus kuwanae (Coleoptera: Coccinellidae) (Zhang et al., 2009). Furthermore, more parasitic wasps of the family Braconidae were attracted to MEJA-baited traps than unbaited traps in field trials (James, 2005). Another braconid, Cotesia plutellae, a larval parasitoid of Plutella xylostella (Lepidoptera: Yponomeutidae), preferred MEJA in Y-tube olfactometer tests (Ibrahim et al., 2005). Based on either single-dose studies of jasmonates or the targeting of single organisms under controlled conditions, the majority-opinion in the literature is that MEJA and other jasmonates are repellent to herbivores and attractant to their natural enemies (Birkett et al., 2000; Bruce et al., 2003; El-Wakeil et al., 2010; Dewhirst et al., 2012; ElWakeil and Volkmar, 2012; Egger and Koschier, 2014). However, more studies of the effects of plant defense elicitors under field conditions are needed to elucidate whether they are useful tools for integrated pest management strategies.

Here, we investigated the influence of different MEJA doses on the population densities of wheat insect pests (aphids, thrips and wheat stem sawflies) and their natural enemies (aphid parasitoids, lady beetles, hoverflies and Collyria coxator) in two different plant growth stages. Population fluctuations were monitored by employing three different sampling methods, direct visual sampling, sweep-net sampling and colored (yellow and blue) sticky traps.

\section{Materials and methods}

\section{Experimental design}

Two years (2012 and 2013) of field experiments were conducted in a wheat field (Triticum aestivum L., cv. Pehlivan, the most commonly sown cultivar) established on alluvial soil under semi-arid climate conditions (Diyarbakir, Turkey 37०54'16"N; $40^{\circ} 16^{\prime} 46^{\prime \prime E}$ ). Standard agronomic practices (e.g., fertilization) were made in our experimental plots. No pesticides were used in our experimental plots throughout of the study. The experimental system consisted of wheat plots established in a randomized complete block design. Each plot was $3 \times 3 \mathrm{~m}^{2}$ (4 replications) and $4 \times 2 \mathrm{~m}^{2}$ (3 replications) in 2012 and 2013, respectively. The distance between experimental plots and other cultivated or non-cultivated areas was at least $2 \mathrm{~m}$. 


\section{Exogenous MEJA treatments}

Plants were treated with MEJA ( $\geq 96 \%$ purity) (Sigma-Aldrich) twice in each year (2012 and 2013). The first and second treatments were performed at wheat growth stages GS-37 $7^{\text {th }}$ (flag leaf just visible, still rolled) and GS-59 ${ }^{\text {th }}$ (End of heading: inflorescence fully emerged) according to $\mathrm{BBCH}$ scale for cereals, respectively (Witzenberger et al., 1989; Lancashire et al., 1991). Three doses of MEJA (14.2 mM, $7.1 \mathrm{mM}$ and $3.55 \mathrm{mM}$, of which the highest dose was applied by McEwen (2011) to cruciferous plants) were employed as the first treatment in year 1 . However, we lowered the doses to $3.55 \mathrm{mM}, 1.76 \mathrm{mM}$ and $0.88 \mathrm{mM}$ for all subsequent treatments (i.e. the second treatment of year 1 and both treatments of year 2) due to high phytotoxic effects observed one day after the first treatment of year 1. Silwet Gold (Chemtura) surfactant at a ratio of $10 \mathrm{ml}$ per $100 \mathrm{~L}$ of water was added to each dose in all treatments. Plants in control plots were treated with distilled water and surfactant only. A hydraulic backpack sprayer was used to apply the treatments.

\section{Sampling methods}

\section{Direct visual samplings}

Presence of phytophagous and entomophagous insects was checked on all aboveground parts of ten plants. All biological forms, i.e. from egg to adult, were checked by using a $5 \times$ hand magnifier and recorded. Samplings were carried out 1 day prior to and 1, 3, 10 and 17 days after the MEJA treatments. There was a 4-day interval between the last sampling of the first treatment period and the first sampling of the second treatment period in both years.

\section{Sweep-net samplings}

A standard sampling net $(\mathrm{R}=35 \mathrm{~cm})$ was used to sweep samples from the experimental plots uniformly. The collected samples were put into clear plastic bags with a paper towel to reduce humidity and then labeled. The samples were transferred to the laboratory and put in a freezer $\left(-20^{\circ} \mathrm{C}\right)$. All specimens were recorded afterward. Sweep-net sampling intervals were the same as those of the direct visual samplings.

\section{Colored sticky trap samplings}

Yellow and blue sticky traps (Kapar Organic, $20 \times 25 \mathrm{~cm}$ ) were placed in the middle of MEJA-treated and untreated control plots one week prior to the first samplings in both years to sample the population densities of flying wheat insect pests and their natural enemies. Data concerning the insects caught by the traps were recorded. The traps were cleaned with a wooden spatula and the insect-catching sticky substrate (Kapar Organic) was renewed when needed. The sampling intervals for the colored sticky traps were the same as those of the direct visual samplings, except that no samplings were conducted on day 1 after the treatments.

\section{Effects of MEJA on agronomic properties}

Seventy-five randomly chosen heads were collected from each plot in mid-June, at harvest time. Grains were extracted from the heads and separated from the glume by 
hand. Grains were kept under laboratory conditions until weighed. In addition, the heights of 10 wheat plants per plot were measured at the the GS $92^{\text {nd }}$ (over-ripe: grain very hard, cannot be dented by thumbnail) according to $\mathrm{BBCH}$ scale.

\section{Statistical analysis}

All $\log (n+1)$ tranformed experimental data were checked for normality (ShapiroWilk's test) and homogeneity of variances (Levene's test) before analysis. To reveal effects of MEJA treatments on wheat insect pests and their natural enemies, data of each year and treatment periods were analyzed by fitting generalized linear mixed models (GLMM, lme4 package) with poisson error distribution (log link function) (Diggle et al., 2002, Bolker et al., 2009, Bates et al., 2015). MEJA doses were fixed factor whereas sampling dates were random factor for all cases. The fixed factor effects were tested using likelihood-ratio (LR) tests $(\mathrm{p}<0.05)$. Tukey's post hoc tests were used to compare the means at the $95 \%$ confidence level (with the glht function of the multcomp package). The effects of MEJA treatment on plant height and yield were analyzed with one-way ANOVA. Means of all data were separated using the Tukey's multiple comparison test at the $95 \%$ confidence level. Insect taxa which did not respond to MEJA treatment in any treatment period or experimental year are not presented in the figures, but their statistical results are presented in Table 1. All statistical analyses were performed with R software, version 3.4.0 (R Core Team, 2017).

\section{Results}

\section{Effects of different methyl jasmonate doses on some insect pests}

\section{Aphid species (Hemiptera: Aphididae)}

There were two aphid species in our experimental area, Sitobion avenae (F.) and Rhopalosiphum padi (L.).

Direct visual samplings of apterous aphids: Generalized linear mixed model analysis revealed that the aphid densities in MEJA $(0.88 \mathrm{mM}$ and $3.55 \mathrm{mM})$-treated wheat plots were lower than in control plots for the second treatment period and pooled whole season of year $1\left(\chi_{2012-\mathrm{ST}}^{2}=89.94, P<0.001, \chi^{2}\right.$ 2012-whole $=87.10, P<0.001 ;$ Fig. $\left.1 A\right)$. Data of the first treatment period of year 1 showed no significant differences among MEJA dose treatments $(P>0.05$, Table 1$)$. The population densities of aphid species on MEJA-treated and untreated plants were not different in the pooled whole-season and data of both treatment periods of year $2(P>0.05$, Table 1$)$.

Sweep-net sampling for apterous aphids: The population densities of apterous aphids swept from MEJA-treated and untreated control plants were not significantly different throughout the study. No apterous aphids were sampled in the first treatment period of year $2(P>0.05$, Table 1$)$.

Direct visual sampling of alate aphids: Data of whole season of year 1 demonstrated significant differences between the mean densities of alate aphids in MEJA-treated and control plants while alate aphid densities did not differ between treatments for first and second treatment periods $\left(\chi^{2}{ }_{2012-\mathrm{FT}}=1.83, P=0.607 ; \chi^{2}{ }_{2012-\mathrm{ST}}=4.15, P=0.245 ; \chi^{2}{ }_{2012}\right.$ whole $=18.66, P<0.001$; Fig. $1 B$ ). However, there were no significant differences between alate aphids visually counted on plants between MEJA-treated plants and controls in year $2(P>0.05$, Table 1$)$. Furthermore, we did not encounter any alate aphid individuals on any experimental plants in the second treatment period of year 2 . 
Table 1. Summary of the data analysis (GLMM) indicating the influence of methyl jasmonate (MEJA) treatments on some insect species sampled by different sampling methods (data pooled over sampling intervals within treatment periods and whole season). NI: no insect recorded $(d f=3$ for all cases $)$

\begin{tabular}{|c|c|c|c|c|c|c|c|c|}
\hline \multirow{2}{*}{ Pest insects } & \multirow[b]{2}{*}{ Year } & \multirow{2}{*}{ Sampling method } & \multicolumn{2}{|c|}{ First treatment } & \multicolumn{2}{|c|}{ Second treatment } & \multicolumn{2}{|c|}{ Whole season } \\
\hline & & & $\chi^{2}$ & $P$ & $\chi^{2}$ & $P$ & $\chi^{2}$ & $P$ \\
\hline \multirow{4}{*}{ Apterous aphids } & \multirow[t]{2}{*}{2012} & \multirow{4}{*}{$\begin{array}{c}\text { Visual Sampling } \\
\text { Sweep-net } \\
\text { Visual sampling } \\
\text { Sweep-net } \\
\end{array}$} & 3.52 & 0.317 & 89.94 & $<0.001$ & 87.10 & $<0.001$ \\
\hline & & & 0.86 & 0.833 & 6.76 & 0.079 & 5.56 & 0.134 \\
\hline & \multirow[t]{2}{*}{2013} & & 3.02 & 0.387 & 6.24 & 0.100 & 2.57 & 0.460 \\
\hline & & & NI & & 2.72 & 0.435 & 5.13 & 0.162 \\
\hline \multirow{6}{*}{ Alate aphids } & \multirow[t]{6}{*}{2012} & \multirow{6}{*}{$\begin{array}{l}\text { Visual sampling } \\
\text { Sweep-net } \\
\text { Yellow traps } \\
\text { Visual sampling } \\
\text { Sweep-net } \\
\text { Yellow traps } \\
\end{array}$} & 1.83 & 0.607 & 4.15 & 0.245 & 18.66 & $<0.001$ \\
\hline & & & 2.34 & 0.504 & 3.77 & 0.286 & 5.53 & 0.136 \\
\hline & & & 2.02 & 0.567 & 0.46 & 0.925 & 1.53 & 0.675 \\
\hline & & & 3.02 & 0.387 & NI & & 0.02 & 0.999 \\
\hline & & & 2.92 & 0.403 & 4.12 & 0.248 & 5.21 & 0.156 \\
\hline & & & 12.16 & 0.006 & 19.98 & $<0.001$ & 15.16 & 0.001 \\
\hline \multirow{4}{*}{ Thrips } & \multirow{4}{*}{$\begin{array}{l}2012 \\
2013\end{array}$} & \multirow{4}{*}{$\begin{array}{c}\text { Visual sampling } \\
\text { Sweep-net } \\
\text { Visual sampling } \\
\text { Sweep-net } \\
\end{array}$} & 3.30 & 0.346 & 1.81 & 0.612 & 1.63 & 0.651 \\
\hline & & & 17.67 & $<0.001$ & 19.22 & $<0.001$ & 31.50 & $<0.001$ \\
\hline & & & 3.02 & 0.387 & 1.01 & 0.796 & 0.08 & 0.993 \\
\hline & & & 1.97 & 0.577 & 1.81 & 0.612 & 2.74 & 0.433 \\
\hline \multirow{6}{*}{ Wheat stem sawflies } & \multirow[t]{6}{*}{2012} & \multirow{6}{*}{$\begin{array}{l}\text { Sweep-net } \\
\text { Yellow traps } \\
\text { Blue traps } \\
\text { Sweep-net } \\
\text { Yellow traps } \\
\text { Blue traps } \\
\end{array}$} & 2.41 & 0.490 & 2.64 & 0.450 & 2.32 & 0.508 \\
\hline & & & 16.55 & $<0.001$ & 44.33 & $<0.001$ & 47.34 & $<0.001$ \\
\hline & & & 1.45 & 0.693 & 5.31 & 0.150 & 2.63 & 0.451 \\
\hline & & & 2.44 & 0.485 & 1.45 & 0.693 & 2.80 & 0.423 \\
\hline & & & 5.08 & 0.165 & 1.53 & 0.673 & 0.39 & 0.940 \\
\hline & & & 0.20 & 0.649 & 4.28 & 0.232 & 4.43 & 0.218 \\
\hline Natural enemies & & & & & & & & \\
\hline \multirow{6}{*}{ Aphid parasitoids } & 2012 & Visual Sampling & 0.32 & 0.954 & 1.53 & 0.673 & 1.80 & 0.614 \\
\hline & & Sweep-net & 1.28 & 0.733 & 5.68 & 0.128 & 4.89 & 0.179 \\
\hline & & Yellow traps & 0.42 & 0.934 & 1.65 & 0.646 & 0.39 & 0.941 \\
\hline & 2013 & Visual Sampling & 2.66 & 0.445 & 3.02 & 0.388 & 0.03 & 0.998 \\
\hline & & Sweep-net & 1.29 & 0.729 & 1.81 & 0.612 & 3.62 & 0.305 \\
\hline & & Yellow traps & 0.40 & 0.938 & 1.53 & 0.673 & 0.39 & 0.940 \\
\hline & 2012 & Visual sampling & NI & & 20.95 & $<0.001$ & 20.22 & $<0.001$ \\
\hline & & Swee & 3.15 & 0.367 & 4.65 & 0.198 & 5.27 & 0.152 \\
\hline & & ellow traps & 1.44 & 0.694 & 13.92 & 0.003 & 12.31 & 0.006 \\
\hline Ladvbirds & & Blue & NI & & 1.53 & 0.673 & 1.40 & 0.704 \\
\hline & 2013 & Visual sampling & 2.02 & 0.567 & 1.45 & 0.693 & 0.29 & 0.960 \\
\hline & & Sweep-net & 3.38 & 0.336 & 1.37 & 0.710 & 2.10 & 0.551 \\
\hline & & Yellow traps & 2.66 & 0.445 & 1.81 & 0.612 & 2.90 & 0.406 \\
\hline & & Blue traps & NI & & 3.56 & 0.312 & 3.44 & 0.327 \\
\hline & 2012 & Sweep-net & 3.15 & 0.367 & 2.19 & 0.533 & 3.22 & 0.357 \\
\hline & & Yellow traps & 1.44 & 0.694 & 6.13 & 0.105 & 4.73 & 0.192 \\
\hline Surnbid flios & & Blue traps & 6.72 & 0.081 & 23.09 & $<0.001$ & 24.80 & $<0.001$ \\
\hline 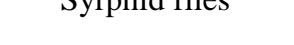 & 2013 & Sweep-net & 4.98 & 0.172 & 1.61 & 0.655 & 1.45 & 0.693 \\
\hline & & Yellow traps & 6.02 & 0.110 & 0.57 & 0.901 & 2.86 & 0.412 \\
\hline & & Blue traps & 6.65 & 0.083 & 2.19 & 0.530 & 3.84 & 0.278 \\
\hline & 2012 & Sweep-net & 10.64 & 0.013 & 0.88 & 0.827 & 10.07 & 0.017 \\
\hline & & Yellow traps & 13.19 & 0.004 & 29.64 & $<0.001$ & 41.11 & $<0.001$ \\
\hline & & Blue traps & 2.94 & 0.400 & 1.47 & 0.688 & 3.89 & 0.273 \\
\hline c. coxator & 2013 & Sweep-net & 5.77 & 0.123 & 0.57 & 0.901 & 6.12 & 0.105 \\
\hline & & Yellow traps & 27.37 & $<0.001$ & 12.11 & 0.006 & 37.31 & $<0.001$ \\
\hline & & Blue traps & 0.48 & 0.92 & 2.93 & 0.402 & 1.74 & 0.627 \\
\hline
\end{tabular}


Sweep-net sampling for alate aphids: There were no significant effects of MEJA treatments on alate aphids collected by sweep-net sampling during the entire experiment $(P>0.05$, Table 1).

Yellow sticky trap samplings for alate aphids: In both treatment periods and pooled whole-season data of year 1 , the population densities of aphid species in MEJAtreated and untreated plants did not differ significantly $(P>0.05$, Table 1$)$. Evaluation of data of the first treatment period of year 2 demonstrated number of aphids caught on yellow traps were higher in $0.88 \mathrm{mM}$ MEJA- treated plots than control plots $\left(\chi^{2} 2013\right.$ FT $=12.16, P=0.006)$. However, $1.76 \mathrm{mM}$ MEJA- treated plots had lower number of alate aphids than control and $0.88 \mathrm{mM}$ MEJA- treated plants in both second treatment period and whole season of year $2\left(\chi^{2}{ }_{2013-\mathrm{ST}}=19.98, P<0.001 ; \chi^{2}\right.$ 2013-whole $=15.16$, $P=0.001 ;$ Fig. 1E).

\section{Phytophagous thrips species}

Eleven phytophagous thrips species belonging to two families of Thysanoptera were recorded during the experiments. The numbers of Haplanthrips tritici (Kurdjumov), $H$. aculeatus (Fabricius) and H. reuteri (Karny) of family Phlaeothripidae were higher than those of Frankliniella tenuicornis (Uzel), Thrips tabaci (Lindeman), Melanthrips pallidior (Priesner), T. angusticeps (Uzel), Kakothrips priesneri (Pelikan), Limothrips cerealium (Haliday), L. angulicornis (Jablonowski) and M. fuscus (Sulzer) of family Thripidae.

Direct visual sampling of phytophagous thrips: There were no significant differences between the population densities of phytophagous thrips species sampled by direct counting on plants in pooled whole-season data and both treatment periods of both years $(P>0.05$, Table 1).

Sweep-net sampling of phytophagous thrips: Evaluation of the first treatment period and whole season data of year 1 revealed that number of thrips in all MEJA treated plots were lower than control plots $\left(\chi^{2}{ }_{2012-\mathrm{FT}}=17.67, \quad P<0.001 ; \chi^{2}\right.$ 2012-whole $=31.50$, $P<0.001$; Fig 1 C). In addition, in year 1, MEJA-treated plants $(0.88 \mathrm{mM})$ had lower population densities of pest thrips than control plants in the second treatment period $\left(\chi_{2012-\mathrm{sT}}^{2}=19.22, P<0.001 ;\right.$ Fig. $\left.1 C\right)$. In contrast, in year 2 , phytophagous thrips populations sampled by sweep-net from MEJA-treated and control plants did not differ significantly based on either pooled whole-season data or treatment periods $(P>0.05$, Table 1).

\section{Wheat stem sawfly species}

Throughout the experiments, two wheat stem sawfly (Hymenoptera: Cephidae) species were collected, of which Cephus pygmaeus (L.) was more prevalent than Trachelus tabidus (F.).

Sweep-net samplings of wheat stem sawfly species: Wheat stem sawfly population densities determined by sweep-net of MEJA-treated and untreated plants were not significantly different for either whole-season pooled data or between treatment periods in both years $(P>0.05$, Table 1$)$.

Yellow sticky trap samplings of wheat stem sawfly species: Yellow sticky trap sampling analysis revealed that the mean densities of wheat stem sawflies in MEJAtreated plants were significantly higher than in control plants in whole-season pooled 
data, the first and the second treatment periods of year $1\left(\chi_{2012-\mathrm{FT}}^{2}=16.55, P<0.001\right.$; $\chi^{2}{ }_{2012 \text {-ST }}=44.33, P<0.001 ; \chi^{2}{ }_{2012 \text {-whole }}=47.34 ; P<0.001 ;$ Fig. $\left.1 D\right)$. In year 2 , there were no significant differences between or among MEJA treatments and/or control plants in both whole-season pooled data and the treatment periods $(P>0.05$, Table 1$)$.

Blue sticky trap sampling of wheat stem sawfly species: The population densities of wheat stem sawflies in MEJA-treated and untreated control plants, as observed by blue sticky traps, did not differ significantly in both whole-season pooled data and the treatment periods of both years $(P>0.05$, Table 1$)$.

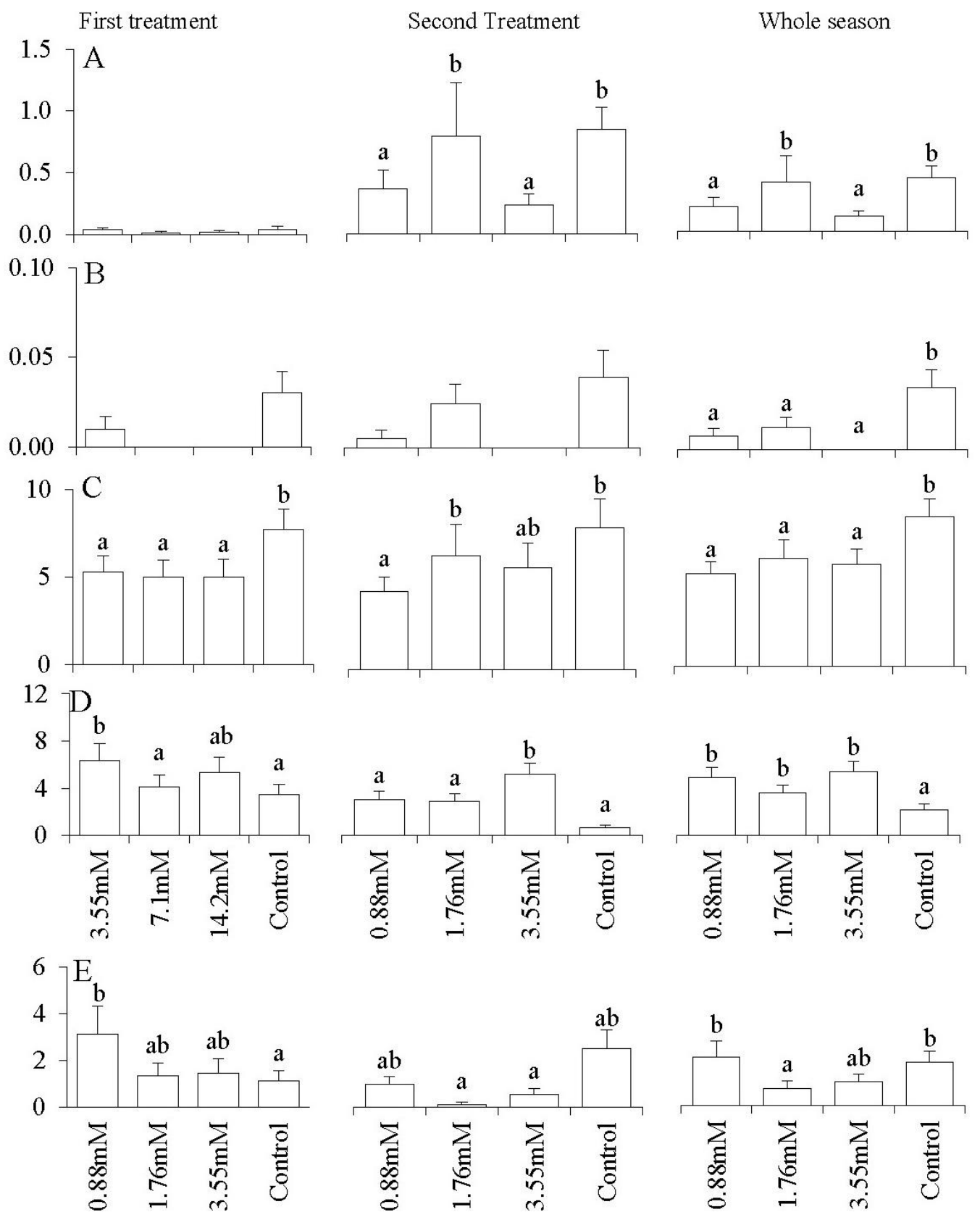

Figure 1. Mean density (+SEM) of apterous aphids per plant in 2012 (A), alate aphids per plant in 2012 (B), pest thrips/ sweep-net in 2012 (C), wheat stem sawflies/yellow traps in 2012 $(D)$ and alate aphids/yellow traps in 2013 (E) in wheat plots treated with different methyl jasmonate doses for first-treatment and second-treatment periods and whole season (Means capped with different letters differ significantly, Tukey's multiple comparison test, $P<0.05$ ) 


\section{Effects of methyl jasmonate treatments on parasitoids and predators of wheat pests}

\section{Aphid parasitoids}

Three braconid aphid parasitoids, Aphidius ervi, Praon gallicum (Stary) and Binodoxys acalephae (Marshall) were collected during our experiments, and A. ervi was the most prevalent species.

Direct visual samplings for aphid parasitoids: There were no differences in the population densities of aphid parasitoids in MEJA- treated and control plants in wholeseason pooled data and the treatment periods of year 1 and year $2(P>0.05$, Table 1$)$.

Sweep-net samplings for aphid parasitoids: The population densities of aphid parasitoids in MEJA- treated and untreated plants determined by sweep-net samplings were not significantly different in both pooled seasonal data and the treatment periods throughout the study $(P>0.05$, Table 1$)$.

Yellow sticky trap sampling of aphid parasitoids: Yellow sticky trap sampling results demonstrated that the population densities of aphid parasitoids in MEJA-treated and untreated plants were not significantly different in both pooled whole season data and the treatment periods $(P>0.05$, Table 1$)$.

\section{Lady beetles (Coleoptera: Coccinellidae)}

Three predatory lady beetle (Coleoptera: Coccinellidae) species were recorded throughout our study, namely Coccinella septempunctata, Adalia bipunctata (L.) and $C$. undecimpunctata (L.), of which C. septempunctata was the most abundant.

Direct visual samplings of lady beetles: The population density of lady beetles in plants treated with $3.55 \mathrm{mM}$ MEJA was higher than those in the other treatments and the controls for the second treatment period. Accordingly, the density of lady beetles directly sampled on plants treated with highest dose were higher than other treatments and control plots in whole-season pooled data, while no individual lady beetle was recorded in the first treatment period $\left(\chi^{2}\right.$ 2012-ST $=20.95, P<0.001 ; \chi^{2}$ 2012-whole $=20.22$, $P<0.001$; Fig. 2A). MEJA treatments did not have any significant effect on the population densities of lady beetles in year $2(P>0.05$, Table 1$)$.

Sweep-net sampling of lady beetles: Throughout the study, there were no significant differences in population densities of lady beetles determined by sweep-net sampling between MEJA-treated and untreated control plants $(P>0.05$, Table 1$)$.

Yellow sticky trap sampling of lady beetles: The population densities of lady beetles caught on yellow sticky traps in treated and untreated plants did not differ significantly from one another in first treatment period of year 1 and second treatment period and whole-season pooled data of year $2(P>0.05$, Table 1$)$. However, number of lady beetles caught on yellow traps in $3.55 \mathrm{mM}$ MEJA-treated plants were higher than control plots in the second application period and whole season pooled data of year 1 $\left(\chi_{2012-\mathrm{ST}}^{2}=13.92, P=0.003 ; \chi^{2}{ }_{2012 \text {-whole }}=12.31, P=0.006 ;\right.$ Fig. $\left.2 B\right)$.

Blue sticky trap samplings of lady beetles: In the first treatment periods of both years, we did not encounter any lady beetle individuals on blue sticky traps. In the second treatment periods and whole season data of both experimental years, the differences between MEJA-treated and untreated control plants were not significant $(P>0.05$, Table 1$)$. 


\section{Hoverflies (Diptera: Syrphidae)}

The hoverfly species collected consisted of four species, Eupeodes corollae (Fabricius), Sphaerophoria scripta (L.), Melanostoma mellinum (L.) and S. turkmenica (Bankowska). Of these species, E. corollae (F.) was the most prevalent.

Sweep-net samplings of hoverfly species: There were no significant differences in the numbers of hoverflies sampled from MEJA- treated and untreated control plants in both treatment periods and whole-season pooled data of both years $(P>0.05$, Table 1$)$.

Yellow sticky trap samplings of hoverflies: The population densities of hoverfly adults caught on yellow sticky traps were not significantly different between the MEJAtreated and control plants in both experimental years $(P>0.05$, Table 1$)$.

Blue sticky trap sampling of hoverflies: Data of the first treatment period of year 1 showed that there were no significant differences in the numbers of hoverfly adults caught on blue sticky traps between MEJA-treated and untreated plants $(\mathrm{P}>0.05$, Table 1). However, in the second application period, plants treated with $0.88 \mathrm{mM}$ MEJA had a lower number of hoverflies compared to plants treated with other MEJA doses and control plants, which resulted in a significant reduction of the population density in $0.88 \mathrm{mM}$ MEJA-treated plants over all treatments, including controls $\chi^{2}{ }_{2012}$ ST $=23.09, P<0.001 ; \chi^{2}$ 2012-whole $=24.80, P<0.001 ;$ Fig. $2 C$ ). In year 2 , there were no differences between treatments in the whole-season data and the treatment periods $(P>0.05$, Table 1$)$.

A larval parasitoid of wheat stem sawfly species; Collyria coxator (Villers) (Hymenoptera: Ichneumonidae)

Sweep-net samplings of $C$. coxator: The population densities of $C$. coxator on the $14.2 \mathrm{mM}$ MEJA-treated plants were higher than on the control plants in the first treatment period of year 1 , which resulted in an increase of the $C$. coxator population density in plants treated with the highest MEJA dose over all treatments for the wholeseason pooled data $\left(\chi^{2}\right.$ 2012-FT $=10.64, P=0.013 ; \chi^{2}{ }_{2012 \text {-whole }}=10.07, P=0.017 ;$ Fig. $\left.2 D\right)$. However, there were no significant differences between the population densities of $C$. coxator in MEJA-treated and untreated control plants in the second treatment period of year 1 or in the pooled whole-season data and the treatment periods of year $2(P>0.05$, Table 1).

Yellow sticky trap samplings of $C$. coxator: The population densities of $C$. coxator, as determined by yellow sticky traps, were significantly higher on MEJA-treated plants compared to control plants in both whole-season pooled data and the two treatment periods of both experimental years $\left(\chi_{2012-\mathrm{FT}}^{2}=13.19, P=0.004 ; \chi_{2}^{2}{ }_{2012-\mathrm{ST}}=29.64\right.$, $P<0.001 ; \chi_{2}^{2} 2012$-whole $=41.11, P<0.001 ; \chi^{2}{ }_{2013-\mathrm{FT}}=27.37, P<0.001 ; \chi^{2}{ }_{2013-\mathrm{ST}}=12.11$, $P=0.006 ; \chi^{2}$ 2013-whole $=37.31, P<0.001 ;$ Fig. $2 E$ and $\left.2 F\right)$.

Blue sticky trap samplings of $C$. coxator: $C$. coxator population densities, as determined by blue sticky traps, did not differ significantly between MEJA-treated and untreated control plants in both whole-season pooled data and the treatment periods of both years $(P>0.05$, Table 1$)$.

\section{Effects of methyl jasmonate doses on wheat agronomic properties}

The mean weights of 75 heads collected from MEJA-treated plants were significantly lower compared to untreated control plants in year 1 , whereas the year- 2 experiments 
showed no differences between or among treatments $\left(F_{2012}=10.527 ; \mathrm{d} f=3,12\right.$; $P=0.001 ; F_{2013}=2.326 ; \mathrm{d} f=3,8 ; P=0.151 ;$ Fig. 3).
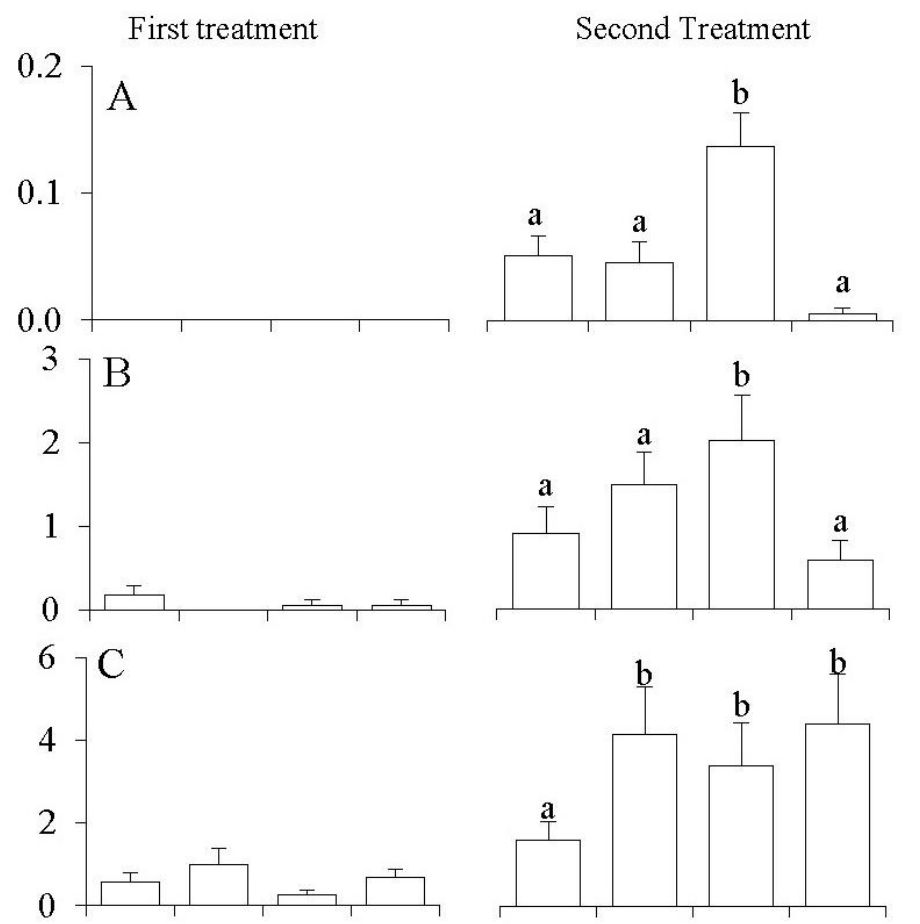

Whole season
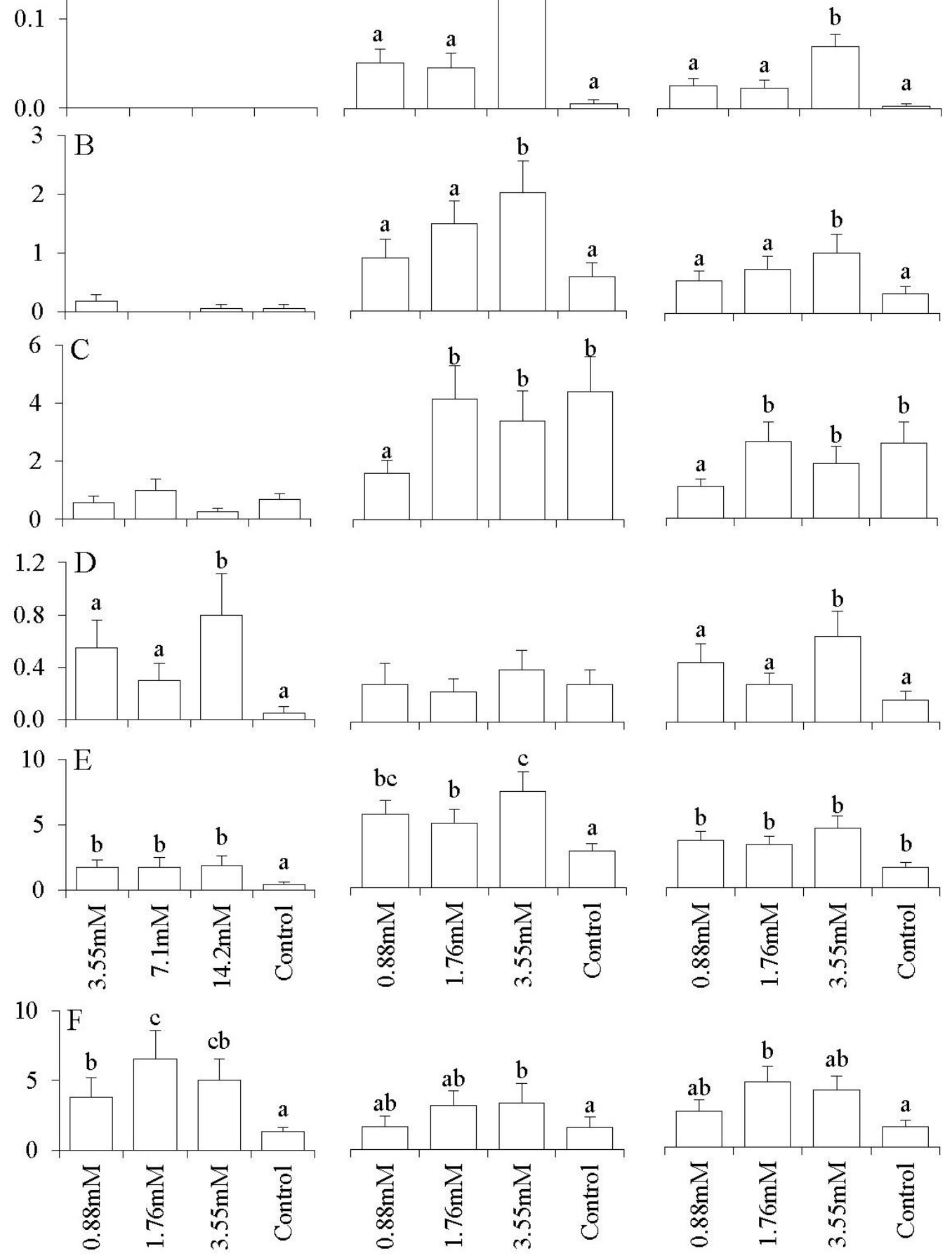

Figure 2. Mean density (+SEM) of ladybeetles per plant in 2012 (A), ladybeetles/yellow traps in 2012 (B), hoverflies/blue traps in $2012(C), C$. coxator/sweep-net in $2012(D), C$. coxator/yellow traps in $2012(E)$ and $2013(F)$ in wheat plots treated with different methyl jasmonate doses for first-treatment and second-treatment periods and whole season (Means capped with different letters differ significantly, Tukey's multiple comparison test, $P<0.05$ ) 


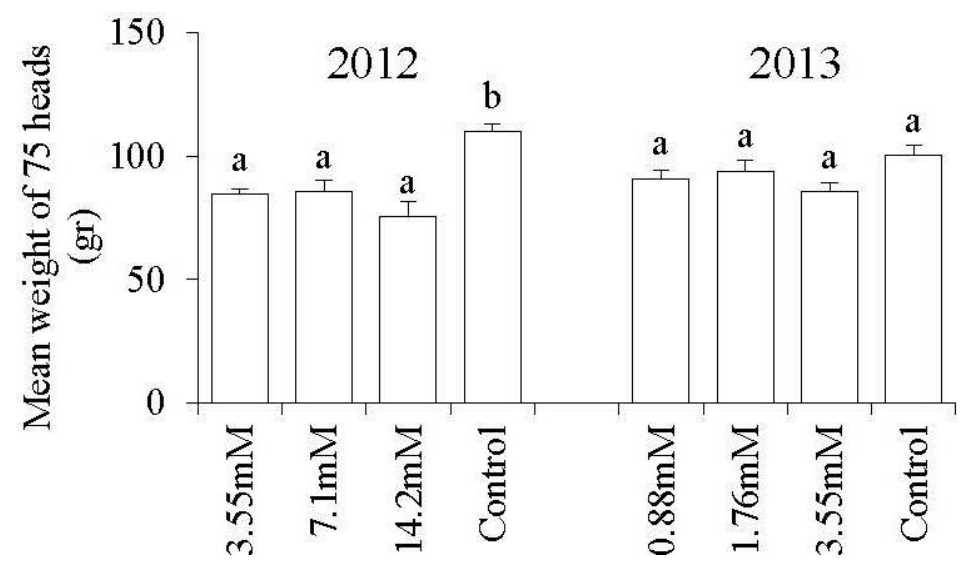

Figure 3. Mean weight (+SEM) of 75 wheat heads from MEJA-treated and untreated control plants in 2012 (year 1) and 2013 (year 2). Means capped with different letters in the same year differ significantly (Tukey's test: $P<0.05$ )

The mean heights of MEJA-treated plants were found to be significantly shorter than those of control plants in both years $\left(F_{2012}=137.859, \mathrm{~d} f=3,156, P<0.001\right.$; $F_{2013}=106.402, \mathrm{~d} f=3,116, P<0.001 ;$ Fig. 4).



Figure 4. Mean height (+SEM) of wheat plants from MEJA-treated and untreated plants in 2012 (year 1) and 2013 (year 2). Means capped with different letters in the same year differ significantly (Tukey's test: $P<0.05$ )

\section{Discussion}

Results of the present study revealed that exogenous MEJA treatments had significant differential effects on both herbivores and their natural enemies in wheat.

\section{Effects of different methyl jasmonate doses on some insect pests}

Aphids

The population densities of apterous and alate aphids on MEJA-treated plants were significantly lower than those on control plants in both years, as assessed by direct visual counting, and the population densities of alate aphids determined by yellow sticky traps in MEJA-treated plants were lower than those of control plants in year 2. 
However, the sweep-net method registered no differences in aphid densities among wheat plants, treated and untreated. Our results of direct visual sampling and yellow trap sampling are in agreement with results of several previous investigations. For example, the population growth of the mustard aphid Lipaphis erysimi on Indian mustard plants (Brassica juncea) was reduced by MEJA treatments (Koramutla et al., 2014). In addition, electronic penetration recording data suggested reduced feeding of apterous $R$. padi on MEJA-treated wheat seedlings, which led to a reduction in the population growth of this pest (Slesak et al., 2001). Another population growth test revealed potential population growth- and performance-suppressing effects of MEJAtreated tomato plants on the phloem feeder M. persicae (Boughton et al., 2006). Also, the number of $R$. padi settling on MEJA-treated barley (cv. Kara) was found to be lower than for unexposed plants during natural daylight (Glinwood et al., 2007). Further tests revealed that reproductive performance of the Russian wheat aphid Diuraphis noxia was lower on barley plants (cv. Makoei) whose parent seeds had been treated with MEJA (Taami and Dolatti, 2013).

Three main jasmonate derivatives - jasmonic acid (JA), cis-jasmone (CJ) and MEJA - are known to have repellent, deterrent and/or antixenotic effects on aphid species attacking cereals and cotton (Omer et al., 2001, Bruce et al., 2003; El-Wakeil et al., 2010; El-Wakeil and Volkmar, 2012). The mechanism behind this aphid resistance is multifold and may be due to: increased hydroxamic acid content and inhibition of trypsin activity in wheat; activation of resistance-related enzymes such as polyphenol oxidase and peroxidase in wheat, tomato and Indian mustard; and up-regulation of jasmonate biosynthetic genes in these plants (Slesak et al., 2001; Boughton et al., 2006; Cao et al., 2014; Koramutla et al., 2014). Wild-type Arabidopsis and a constitutively active jasmonate signaling mutant both repelled $M$. persicae when treated with MEJA (Ellis et al., 2002). However, despite advances in understanding the molecular mechanisms (e.g. in terms of enzymes, non-enzyme proteins and genes) by which exogenous jasmonate treatment deters aphids, much less is known about the effects of MEJA on aphids under natural conditions.

The significant repellent effects of MEJA on aphids, as detected by visual counting (2012) and yellow traps (2013), occurred in different years. Therefore, whether HIPV treatments encourage apterous aphids to produce alate aphids for 'take-off' remains obscure. Factors like colonization, wind, temperature, day length, light density, moisture, host plant growth stage and its quality are known to play roles in aphid migration (Parry, 2013). Further detailed studies are needed to understand whether HIPVs are one of the factors that induce aphids to migrate.

\section{Phytophagous thrips}

The population densities of thrips species on MEJA-treated plants were significantly lower than on control plants in both treatment periods of year 1, according to sweep-net samplings, whereas visual samplings did not reveal any significant difference. To our knowledge, this is the first record of how thrips populations on wheat plants are affected by MEJA treatment, while there is a growing body of evidence on the effects of JA and CJ on thrips populations. For example, JA was found to reduce the population density of thrips species, likely consisting of $\mathrm{H}$. tritici, $\mathrm{H}$. aculeatus, L. denticornis, $F$. teucornis and T. angusticeps, on wheat plants (El-Wakeil et al., 2010; El-Wakeil and Volkmar, 2012). Another study indicated that performance and preference of $F$. occidentalis was 
restricted by JA application on Arabidopsis and Brassica rapa plants (Abe et al., 2009). MEJA and CJ were found to have deterrent effects on second instar larva of $F$. occidentalis on leaf dics of the bean Faseolus vulgaris in choice settlement assays (Egger and Koschier, 2014). In addition, the deterrent effects of jasmonates on feeding and oviposition by thrips were improved when combined with allylanisole (Egger et al., 2014). Jasmonates are also known to induce the formation of glandular trichomes, thus increasing the number of thrips entrapped by these plant-defense structures (Boughton et al., 2005). Furthermore, jasmonate-inducible defenses of tomato plants (i.e. proteinase inhibitors and polyphenol oxidase) were found to attenuate a community of herbivores, including a thrips species, F. occidentalis (Thaler et al., 2001). Apparently, jasmonate applications are responsible for inducing different defense mechanisms in plants and negatively affecting thrips performance and plant preference.

\section{Wheat stem sawflies}

MEJA may be a promising attractant for wheat stem sawfly adults, as their numbers were higher on MEJA-treated plants than on control plants, based on sampling by yellow sticky traps in our study, although data from the other sampling methods did not show significance. However, in our previous study, we found that the outcome of CJ on wheat stem sawflies is influenced by the sampling method, with more consistent results obtained from yellow sticky traps and indicating that $\mathrm{CJ}$ is repellent to wheat stem sawfly adults (Bayram and Tonğa, 2017). CJ-treated wheat plants release a group of HIPVs, one of which ((Z)-3-hexenyl acetate) repels the wheat stem sawfly $C$. cinctus at high doses while attracting it at lower concentrations (Piesik et al., 2008; Delaney et al., 2013). The same very high MEJA doses that we used in our study induced faster maturation of wheat plants in another study (Beltrano et al., 1998); therefore, in our field experiments, such faster growth may have limited the production of HIPVs like (Z)-3-hexenyl acetate, causing the compounds to remain at attractive (lower) concentrations after MEJA treatment. Nevertheless, such opposite results for chemicals belonging to the same biosynthetic pathway could be beneficial to "trap and kill" or "push-pull" pest management systems. In our studies, we did not assess ovipositionrelated parameters, e.g., eggs laid in each plant or the number of wheat stem sawfly females trapped. However, discovering the roles of HIPVs in the ovipositional behavior of wheat stem sawflies could help in developing these control strategies.

\section{Effects of methyl jasmonate treatments on parasitoids and predators of wheat pests}

\section{Aphid parasitoids}

The population densities of aphid parasitoids sampled from different MEJA-treated wheat plants in this study were not significantly different from those of control plants. In a previous field experiment, MEJA-baited traps were found to be attractive to parasitoids from the family Braconidae (James, 2005). Electroantennogram studies revealed that the parasitic braconid wasp Microplitis croceipes responds to MEJA (Park et al., 2001). Testing of CJ on aphid parasitoids showed it to be an attractant. For example, in wind tunnel studies, $A$. ervi was attracted to vapor exposure of CJ-treated Vicia faba plants (Birkett et al., 2000). Moreover, plant defenses induced by CJ in Arabidopsis attracted A. ervi, a generalist aphid parasitoid, but had no influence on Diaeretiella rapae, a specialist aphid parasitoid (Bruce et al., 2008). Dewhirst et al. 
(2012) found that HIPVs released from CJ-applied Capsicum annum plants were preferred by $A$. ervi and encouraged its foraging time. To our knowledge, the present study is the first report of aphid parasitoid responses to MEJA under field conditions. Our data are not in agreement with the above-mentioned CJ studies, but this could be due to the different jasmonate derivates investigated, the different species studied (host plant, insect pest, parasitoid), the phytotoxic effects of the MEJA doses, experiment type and/or ecological factors.

\section{Lady beetles}

Direct visual and yellow trap samplings showed that there were significant attractive effects of MEJA treatments on lady beetles, although these effects were not found based on sweep-net and blue sticky trap samplings. A previous study showed that persimmon plants infested with the herbivorous Japanese wax scale, Ceroplastes japonicus (Hemiptera: Coccidae), and persimmon plants treated with MEJA, released the terpenoid $\alpha$-pinene, which was found to be a strong attractant to virgin female lady beetles of the species Chilocorus kuwanae (Coleoptera: Coccinellidae) (Zhang et al., 2009). In addition, an earlier study reported that CJ-impregrated filter papers were preferred over control arms by the seven-spotted lady beetle C. septempunctata in olfactometer studies (Birkett et al., 2000).

\section{Hoverflies}

The blue sticky trap sampling results in our study, but none of the other sampling methods we used, indicated an effect of MEJA on hoverflies (adults), suggesting a possible deterrent effect. In an earlier study, hoverflies did not positively respond to MEJA-baited traps in field tests (James, 2005). Thaler, (2002) found that JA-reduced aphid density was correlated with reduced numbers of hoverfly eggs, supporting the theory that hoverflies mostly employ visual cues to locate their hosts. Studies on the behavioral responses of Episyrphus balteatus, another hoverfly species, revealed that this hoverfly employs a composition of cues consisting of plant volatiles (i.e., green leaf volatiles and terpenoids) and a host pheromone(s) (Verheggen et al., 2008). Exogenous CJ application caused wheat plants to release volatiles such as (Z)-3-hexen-1-ol, which was found to contribute to host-plant locating and ovipositional behavior of the hoverflies (Verheggen et al., 2008; Delaney et al., 2013). A possible explanation is that the phytotoxic effects of MEJA may change both the chemical profile and the visual appearance of plants so that hoverflies may fail to locate their prey.

\section{Collyria coxator}

The population densities of $C$. coxator, a wheat stem sawfly larval parasitoid, were significantly higher in MEJA-treated wheat plants compared to control plants, according to both sweep-net and yellow sticky trap samplings. Our previous findings indicated that $\mathrm{CJ}$ is similarly attractive to $C$. coxator adults in field experiments (Bayram and Tonğa, 2017). The chemical ecology of $C$. coxator is not well-known. Thus, further investigations indicating how $C$. coxator adults respond either to jasmonates or to changes in the chemical profile of wheat after jasmonate treatment are highly suggested. 


\section{Agronomic properties}

Results of our experiments revealed that MEJA applications significantly reduced wheat yield. Our findings confirm previous results by Beltrano et al. (1998). They reported that MEJA treatments accelerated wheat senescence and shortened the grainfilling period, resulting in reduced yield. Similar yield-decreasing effects of MEJA were also observed in rice (Kim et al., 2009a). However, the inflence of MEJA on plants can vary; for example, MEJA-treated rice and wheat plants under drought conditions had higher yields (Kim et al., 2009b; Anjum et al., 2016). Therefore, the effects of MEJA might be dependent on environmental conditions such as drought or MEJA dosage, where high doses are phytotoxic (Boughton et al., 2006; Anjum et al., 2016). We observed such phytotoxic effects in the present study, in that the heights of plants (the above-ground parts) treated with MEJA grew shorter than those of untreated control plants. These results are concordant with previous investigations in which it was found that MEJA treatments stunted the height of Scots pine (Pinus sylvestris L., Pinaceae) seedlings (Heijari et al., 2005).

Our results indicate that exogenously applied MEJA could act as a repellent against some piercing-sucking wheat pests (aphids and thrips) and as an attractant for wheat stem sawfly adults. In addition, some natural enemies of insect herbivores (lady beetles and $C$. coxator) were attracted to MEJA-treated plants whereas hoverflies were repelled and braconid aphid parasitoids were not affected either way. These results could be exploited to benefit integrated pest management programs, especially in push-pull strategies, when a certain pest is targeted. The effects of MEJA doses on different species varied depending on the plant growth stage. MEJA doses tested in our study had adverse effects on some agronomic features of wheat. Therefore, our results suggest that the roles of lower doses of MEJA in plant defense induction should be taken into consideration in future studies. Our study lacks of phytochemical analysis of wheat volatile chemical changes after MEJA treatment, so that further studies providing such data are needed to support our field-experiment findings.

Acknowledgements. Dicle University, Scientific Research Projects Coordination supported this research financially (Project number: 12-ZF-28). We wish to thank to Mr Eyyüp Can Ağaç, Mr Servet ÜRÜN and Mr Kadri Şeker for their assistance during experiments. We are grateful to Prof. Dr. Ekrem Atakan (Cukurova University, Adana, TR), Prof. Dr. Rüstem Hayat (Suleyman Demirel University, Isparta, TR), Prof. Dr. Petr Starý (Biology Centre of the Academy of Sciences of the Czech Republic) and Dr. Mahir Budak (Cumhuriyet University, Sivas, TR) for their help in species identification.

\section{REFERENCES}

[1] Abe, H., Shimoda, T., Ohnishi, J., Kugimiya, S., Narusaka, M., Seo, S., Narusaka, Y., Tsuda, S., Kobayashi, M. (2009): Jasmonate-dependent plant defense restricts thrips performance and preference. - BMC Plant Biology 9: 97.

[2] Anjum, S. A., Tanveer, M., Hussain, S., Tung, S. A., Samad, R. A., Wang, L., Khan, I., ur Rehman, N., Shah, A. N., Shahzad, B. (2016): Exogenously applied methyl jasmonate improves the drought tolerance in wheat imposed at early and late developmental stages. - Acta Physiologiae Plantarum 38(1): 25.

[3] Avdiushko, S. A., Brown, G. C., Dahlman, D. L., Hildebrand, D. F. (1997): Methyl jasmonate exposure induces insect resistance in cabbage and tobacco. - Environmental Entomology 26(3): 642-654. 
[4] Bayram, A., Tonğa A. (2017): cis-Jasmone treatments affect pests and beneficial insects of wheat (Triticum aestivum L.): the influence of doses and plant growth stages. - Crop Protection (https://doi.org/10.1016/j.cropro.2017.11.011).

[5] Bates, D., Maechler, M., Bolker, B., Walker, S., (2015): Fitting Linear Mixed-Effects Models Using lme4. - Journal of Statistical Software 67(1): 1-48.

[6] Beltrano, J., Ronco, M. G., Montaldi, E. R., Carbone, A. (1998): Senescence of flag leaves and ears of wheat hastened by methyl jasmonate. - Journal of Plant Growth Regulation 17(1): 53-57.

[7] Birkett, M. A., Campbell, C. A., Chamberlain, K., Guerrieri, E., Hick, A. J., Martin, J. L., Matthes, M., Napier, J. A., Pettersson, J., Pickett, J. A., Poppy, G. M. (2000): New roles for cis-jasmone as an insect semiochemical and in plant defense. - Proceedings of the National Academy of Sciences 97(16): 9329-9334.

[8] Bolker, B. M., Brooks, M. E., Clark, C. J., Geange, S. W., Poulsen, J. R., Stevens, M. H. H, White, J. S. S. (2009): Generalized linear mixed models: a practical guide for ecology and evolution. - Trends in Ecology and Evolution 24(3): 127-135.

[9] Boughton, A. J., Hoover, K., Felton, G. W. (2005): Methyl jasmonate application induces increased densities of glandular trichomes on tomato, Lycopersicon esculentum. - Journal of Chemical Ecology 31(9): 2211-2216.

[10] Boughton, A. J., Hoover, K., Felton, G. W. (2006): Impact of chemical elicitor applications on greenhouse tomato plants and population growth of the green peach aphid, Myzus persicae. - Entomologia Experimentalis et Applicata 120(3): 175-188.

[11] Bruce, T. J., Martin, J. L., Pickett, J. A., Pye, B. J., Smart, L. E., Wadhams, L. J. (2003): cis-Jasmone treatment induces resistance in wheat plants against the grain aphid, Sitobion avenae (Fabricius) (Homoptera: Aphididae). - Pest Management Science 59(9): 10311036.

[12] Bruce, T. J., Matthes, M. C., Chamberlain, K., Woodcock, C. M., Mohib, A., Webster, B., Smart, L. E., Birkett, M. A., Pickett, J. A., Napier, J. A. (2008): cis-Jasmone induces Arabidopsis genes that affect the chemical ecology of multitrophic interactions with aphids and their parasitoids. - Proceedings of the National Academy of Sciences 105(12): 4553-4558.

[13] Brunissen, L., Vincent, C., Le Roux, V., Giordanengo, P. (2010): Effects of systemic potato response to wounding and jasmonate on the aphid Macrosiphum euphorbiae (Sternorryncha: Aphididae). - Journal of Applied Entomology 134(7): 562-571.

[14] Cao, H. H., Wang, S. H., Liu, T. X. (2014): Jasmonate- and salicylate-induced defenses in wheat affect host preference and probing behavior but not performance of the grain aphid, Sitobion avenae. - Insect Science 21(1): 47-55.

[15] Delaney, K. J., Wawrzyniak, M., Lemańczyk, G., Wrzesińska, D., Piesik, D. (2013): Synthetic cis-jasmone exposure induces wheat and barley volatiles that repel the pest cereal leaf beetle, Oulema melanopus L. - Journal of Chemical Ecology 39(5): 620-629.

[16] Dewhirst, S. Y., Birkett, M. A., Loza-Reyes, E., Martin, J. L., Pye, B. J., Smart, L. E., Hardie, J., Pickett, J. A. (2012): Activation of defence in sweet pepper, Capsicum annum, by cis-jasmone, and its impact on aphid and aphid parasitoid behaviour. - Pest Management Science 68(10): 1419-1429.

[17] Diggle, P., Heagerty, P., Liang KL., Zeger, S., (2002): Analysis of Longitudinal Data. Oxford University Press Second Edition, Oxford.

[18] Egger, B., Koschier, E. H. (2014): Behavioural responses of Frankliniella occidentalis Pergande larvae to methyl jasmonate and cis-jasmone. - Journal of Pest Science 87(1): 53-59.

[19] Egger, B., Spangl, B., Koschier, E. H. (2014): Habituation in Frankliniella occidentalis to deterrent plant compounds and their blends. - Entomologia Experimentalis et Applicata 151(3): 231-238.

[20] Ellis, C., Karafyllidis, I., Turner, J. G., (2002): Constitutive activation of jasmonate signaling in an Arabidopsis mutant correlates with enhanced resistance to Erysiphe 
cichoracearum, Pseudomonas syringae, and Myzus persicae. - Molecular Plant-Microbe Interactions 15(10): 1025-1030.

[21] El-Wakeil, N. E., Volkmar, C. (2012): Effect of jasmonic application on economically insect pests and yeald in spring wheat. - Gesunde Pflanzen 64(3): 107-116.

[22] El-Wakeil, N. E., Volkmar, C., Sallam, A. A. (2010): Jasmonic acid induces resistance to economically important insect pests in winter wheat. - Pest Management Science 66(5): 549-554.

[23] Glinwood, R., Gradin, T., Karpinska, B., Ahmed, E., Jonsson, L. M. V., Ninkovic, V. (2007): Aphid acceptance of barley exposed to volatile phytochemicals differs between plants exposed in daylight and darkness. - Plant Signaling \& Behavior 2(5): 321-326.

[24] Heijari, J., Nerg, A. M., Kainulainen, P., Viiri, H., Vuorinen, M., Holopainen, J. K. (2005): Application of methyl jasmonate reduces growth but increases chemical defence and resistance against Hylobius abietis in Scots pine seedlings. - Entomologia Experimentalis et Applicata 115(1): 117-124.

[25] Ibrahim, M. A., Nissinen, A., Holopainen, J. K. (2005): Response of Plutella xylostella and its parasitoid Cotesia plutellae to volatile compounds. - Journal of Chemical Ecology 31(9): 1969-1984.

[26] James, D. G. (2005): Further field evaluation of synthetic herbivore-induced plan volatiles as attractants for beneficial insects. Journal of Chemical Ecology 31(3): 481495.

[27] Kessler, A., Baldwin, I. T. (2001): Defensive function of herbivore-induced plant volatile emissions in nature. - Science 291(5511): 2141-2144.

[28] Kim, E. H., Kim, Y. S., Park, S. H., Koo, Y. J., Do Choi, Y., Chung, Y. Y., Lee, I. J., Kim, J. K. (2009a): Methyl jasmonate reduces grain yield by mediating stress signals to alter spikelet development in rice. - Plant Physiology 149(4): 1751-1760.

[29] Kim, E. H., Park, S. H., Kim, J. K. (2009b): Methyl jasmonate triggers loss of grain yield under drought stress. - Plant Signaling \& Behavior 4(4): 348-349.

[30] Koramutla, M. K., Kaur, A., Negi, M., Venkatachalam, P., Bhattacharya, R. (2014): Elicitation of jasmonate-mediated host defense in Brassica juncea (L.) attenuates population growth of mustard aphid Lipaphis erysimi (Kalt.). - Planta 240(1): 177-194.

[31] Lackman, P., González-Guzmán, M., Tilleman, S., Carqueijeiro, I., Pérez, A. C., Moses, T., Seo, M., Kanno, Y., Häkkinen, S. T., Van Montagu, M. C., Thevelein, J. M. (2011): Jasmonate signaling involves the abscisic acid receptor PYL4 to regulate metabolic reprogramming in Arabidopsis and tobacco. - Proceedings of the National Academy of Sciences 108(14): 5891-5896.

[32] Lancashire, P. D., Bleiholder, H., Langelddücke, P., Stauss, R., van den Boom, T., Weber, E., Witzenberger, A. (1991): An uniform decimal code for growth stages of crops and weeds. Annals of Applied Biology 119: 561-601.

[33] Larsson, H. (2005): Economic damage by Limothrips denticornis in rye, triticale and winter barley. - Journal of Applied Entomology 129(7): 386-392.

[34] Mandour, N. S., Kainoh, Y., Ozawa, R., Uefune, M., Takabayashi, J. (2013): Effects of prohydrojasmon-treated corn plants on attractiveness to parasitoids and the performance of their hosts. - Journal of Applied Entomology 137(1-2): 104-112.

[35] McEwen, C. L. (2011): Two entomological studies: 1, The potential of Methyl jasmonate applications as a pest management method on cruciferous crops. 2, Contributions to the biology of Disholcaspis quercusmamma (Walsh) (Hymenoptera: Cynipidae). - Doctoral Dissertation, Colorado State University.

[36] Moraes, M. C., Laumann, R. A., Pareja, M., Sereno, F. T., Michereff, M. F., Birkett, M. A., Pickett, J. A., Borges, M. (2009): Attraction of the stink bug egg parasitoid Telenomus podisi to defence signals from soybean activated by treatment with cis-jasmone. Entomologia Experimentalis et Applicata 131(2): 178-188.

[37] Omer, A. D., Granett, J., Karban, R., Villa, E. M. (2001): Chemically-induced resistance against multiple pests in cotton. - International Journal of Pest Management 47(1): 49-54. 
[38] Park, K. C., Zhu, J., Harris, J., Ochieng, S. A., Baker, T. C. (2001): Electroantennogram responses of a parasitic wasp, Microplitis croceipes, to host-related volatile and anthropogenic compounds. - Physiological Entomology 26(1): 69-77.

[39] Parry, H. R. (2013): Cereal aphid movement: general principles and simulation modelling. - Movement Ecology 1(1): 14.

[40] Piesik, D., Weaver, D. K., Runyon, J. B., Buteler, M., Peck, G. E., Morrill, W. L. (2008): Behavioural responses of wheat stem sawflies to wheat volatiles. - Agricultural and Forest Entomology 10(3): 245-253.

[41] R Core Team (2017): R: A language and environment for statistical computing. - R Foundation for Statistical Computing, Vienna, Austria. https://www.R-project.org/.

[42] Seddigh, S., Bandani, A. R. (2012): Comparison of $\alpha$ and $\beta$-galactosidase activity in the three cereal pests, Haplanthrips tritici Kurdjumov (Thysanoptera: Phlaeothripidae), Rhopalosiphum padi L. (Hemiptera: Aphididae) and Eurygaster integriceps Puton (Hemiptera: Scutelleridae). - Archives of Phytopathology and Plant Protection 46(20): 2443-2449.

[43] Selig, P., Keough, S., Nalam, V. J., Nachappa, P. (2016): Jasmonate-dependent plant defenses mediate soybean thrips and soybean aphid performance on soybean. Arthropod-Plant Interactions 10(4): 273-282.

[44] Slesak, E., Slesak, M., Gabrys, B. (2001): Effect of methyl jasmonate on hydroxamic acid content, protease activity, and bird cherry-oat aphid Rhopalosiphum padi (L.) probing behavior. - Journal of Chemical Ecology 27(12): 2529-2543.

[45] Özberk, İ., Atl1, A., Yücel, A., Özberk, F., Coşkun, Y. (2005): Wheat stem sawfly (Cephus pygmaeus L.) damage; impacts on grain yield, quality and marketing prices in Anatolia. - Crop Protection 24(12): 1054-1060.

[46] Taami, J., Dolatti, L. (2013): Effect of exogenous application of methyl jasmonate on barley resistance to the Russian wheat aphid, Diuraphis noxia (Hemiptera: Aphididae). The Second International Conference on Agriculture and Natural Resources 411-414. December 23-25, 2013, Kermanshah, Iran.

[47] Tan, C. W., Chiang, S. Y., Ravuiwasa, K. T., Yadav, J., Hwang, S. Y. (2012): Jasmonateinduced defenses in tomato against Helicoverpa armigera depend in part on nutrient availability, but artificial induction via methyl jasmonate does not. - Arthropod-Plant Interactions 6(4): 531-541.

[48] Thaler, J. S. (2002): Effect of jasmonate-induced plant responses on the natural enemies of herbivores. - Journal of Animal Ecology 71(1): 141-150.

[49] Thaler, J. S., Stout, M. J., Karban, R., Duffey, S. S. (2001): Jasmonate-mediated induced plant resistance affects a community of herbivores. - Ecological Entomology 26(3): 312324.

[50] Verheggen, F. J., Arnaud, L., Bartram, S., Gohy, M., Haubruge, E. (2008): Aphid and plant volatiles induce oviposition in an aphidophagous hoverfly. - Journal of Chemical Ecology 34(3): 301-307.

[51] Witzenberger, A., Hack, H., van den Boom, T. (1989): Er- läuterungen zum BBCHDezimal-Code für die Entwick-lungsstadien des Getreides - mit Abbildungen. - Gesunde Pflanzen 41: 384-388.

[52] Zhang, Y., Xie, Y., Xue, J., Peng, G., Wang, X. (2009): Effect of volatile emissions, especially $\alpha$-pinene, from Persimmon trees infested by Japanese wax scales or treated with methyl jasmonate on recruitment of Ladybeetle Predators. - Environmental Entomology 38(5): 1439-1445. 